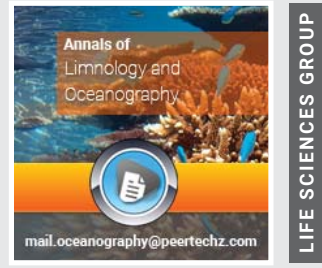

\title{
Origami influence on container design
}

\section{Kleanthis Antoniou and Erkan Oterkus*}

Department of Naval Architecture, Ocean and Marine Engineering, University of Strathclyde, Glasgow100 Montrose Street Glasgow, G4 OLZ, United Kingdom

Received: 10 December, 2019

Accepted: 23 December, 2019

Published: 24 December, 2019

*Corresponding author: Dr. Erkan Oterkus, Professor, Department of Naval Architecture, Ocean and Marine Engineering, University of Strathclyde, Glasgow100 Montrose Street Glasgow, G4 OLZ, United Kingdom, Tel: +44-141-548-3876;

E-mail: erkan.oterkus@strath.ac.uk

Keywords: Origami; Container; Finite element method https://www.peertechz.com

Check for updates

\section{Abstract}

This study examines the capabilities that the origami tradition can contribute to the structural efficiency of a container. Art and tradition meet engineering in an effort to modify the mechanical properties of a conventional design and broaden its potential, as a heavy and sensitive motor is to be transported in a secure way. Using Finite Element Analysis, a thorough research is being conducted, so that an optimal arrangement of different elements can be found. Mechanical hinges, folding that enables expansion and shrinkage, and a layout that inverts the Poisson's ratio of a structure, are some features that are derived by designs that are primarily Origami conceptions. All these are being put to the test, in an investigation of their effect on stress minimization on the proposed model.

\section{Introduction}

Origami, the name of which is a combination of Japanese words Ori(folding) and Kami(paper), is a form of art that traces its roots in ancient Japan, and has been considered an intelligent hobby as it requires fine perception of geometrical figures to obtain the desired result. Only during the last few decades has its presence been spotted in industrial context as it has been discovered to have amazing new capabilities in introducing new mechanical properties to structures or enhancing their existing ones [1-5]. Its advantages in enhancing a structural design has been of use in cases where it is not possible to reinforce the structure with a conventional procedure. Its capability of adding indispensable mechanical attributes to deployable structures opens new possibilities in harsh conditions like the space environment where a combination of maneuverability and durability is a necessary feature.

The introduction of Origami design in engineering applications can be generally categorized into three areas. At first, a lot of deployable structures are inspired from Origami folding. The examples are various and ranging from satellite solar sails to army emergency shelters. Otherwise, folding is used so that an increase in the total stiffness of the structure is achieved with a small addition to the total weight. A famous example is the lightweight sandwich panel cores for aircraft fuselages. In the field of architecture, the same logic is applied in the cases of folded plate roofs or small modifications that complicate the design but add to its strength and sometimes in its aesthetic appearance. Lastly, Origami modifications have been introduced to designs that aim to absorb energy or to resist buckling phenomenon.

The main goal of this study is to develop a novel solution to carry a highly sensitive electrical equipment in container which will be installed in an offshore environment. The proposed solution utilizes the effect of the Origami art tradition in increasing the mechanical attributes of structures. Taking into consideration the Origami contribution, different container geometries are being modelled, tested and compared to obtain a container design with better structural properties than a conventional container design.

\section{Folded textured sheets}

With the introduction of a special texture, such as wrinkles, creases and folds, to a sheet, the global mechanical properties of the structure can be modified. The sheets' most inestimable property is related with their Poisson's ratio. The Eggbox and the Miura sheet have a positive and a negative Poisson's ratio, respectively, in their planar deformation mode. A negative Poisson's ratio is quite extraordinary which is usually only found in foam structures. Both folded textured sheets behave exactly opposite to what is expected from them and their Poisson's ratio is of opposite sign for in-plane stretching and 
out-of-plane bending $[6,7]$. The most obvious property of these sheets is their ability to withstand large deformations in relation to the original sheet as the folds open and close. In addition, this modification enables the sheets to spread or shrink locally and therefore change their global Gaussian curvature (i.e. the inherent degree of curvature of a point in the surface) without any change of the material properties. The interest of this study is on the macroscopic behavior of such sheets as this precious add-on can be integrated in the proposed design.

\section{Equipment details}

The sensitive equipment which is carried by a container is considered as $125 \mathrm{HP} / 90 \mathrm{~kW}$ AESV2E IE2 Motor due to the difficulty that its shipping entails as it is a very heavy item in comparison to its dimensions. The motor has dimensions of $550 \mathrm{~mm} \times 1087.5 \mathrm{~mm} \times 546 \mathrm{~mm}$ and a weight of $1180 \mathrm{~kg}$.

The module will be lifted into place by a heavy lift vessel using a 4-point lift with a spreader frame. The module will finally sit on a support structure, an offshore jacket, and will therefore be rigidly supported. However, during the lifting process it will be subject to deflection which is being investigated in this study. The selected solution requires a large open volume without intruding structures and the floor of the module has a requirement to limit the deflection. The module will be fully clad on all sides; the roof and the under floor in addition to having a steel plate floor internally. Such cladding can be considered as part of the design envelope. The cladding walls need to be outside the structure to provide a smooth outer service to prevent corrosion traps. The roof deflection is governed by normal design practices and needs to be capable of taking the defined loads.

\section{Traditional container design}

Containers have been used for shipping purposes for the biggest part of the $20^{\text {th }}$ century and are still the dominant item for goods transport in the world market today. Their main advantages apart from their ability to withstand loads and store effectively include their shape that helps substantially in storage of big numbers of similar containers. This is why the different designs of typical ISO containers comes in the basic 20' design, in its double, 40' and in variations of its half or quarter, 10' and quadcon containers, respectively. Although the conventional container looks like a complex structure, it is governed by a simple process of expanding a basic connection of beams and columns that create a box with an exterior layer of thin steel (Figure 1). For the purposes of this study, the conventional container has been modelled as a flat surface, as the point of the research conducted is the further folding of the structure. Close to the roof of the structure four hinges are added to simulate the real hinges (Figure 2).

For the structural analysis, Finite Element Method (FEM) is utilized by using ANSYS, a commercial finite element software. For all the numerical analysis performed in this study, the material properties are specified as Young's Modulus of 210GPa, Poisson's ratio of 0.275 and density of 0.8 . The weight of the
IE2 Motor is $1180 \mathrm{~kg}$. This weight is applied as vertical force on the nodes of the meshed internal area of the rectangular structure as shown in Figure 3.

Based on FEM analysis, deformed configuration and Von Mises stress distribution inside the classical container are obtained as presented in Figures 4,5. According to these results, high values of stresses and deflections are observed in the base of the container which should be the first concern for improvement in the following sections. The roof isn't significantly influenced by the load. Therefore, this part will be kept same as in the conventional container.

\section{First design based on origami concept}

The first attempt to reduce the high values of stresses and

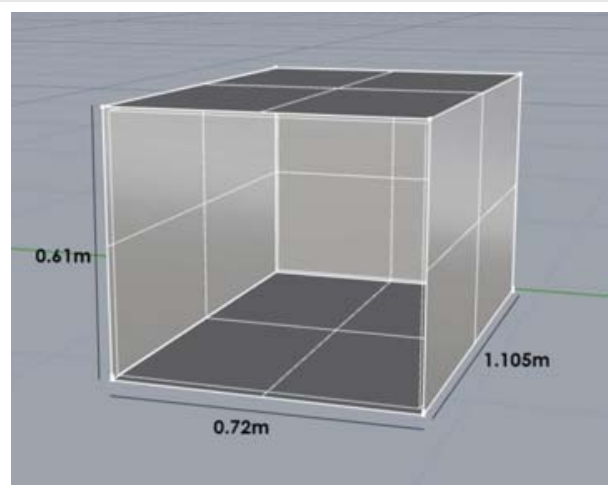

Figure 1: Geometrical properties of the traditional container used in this study.

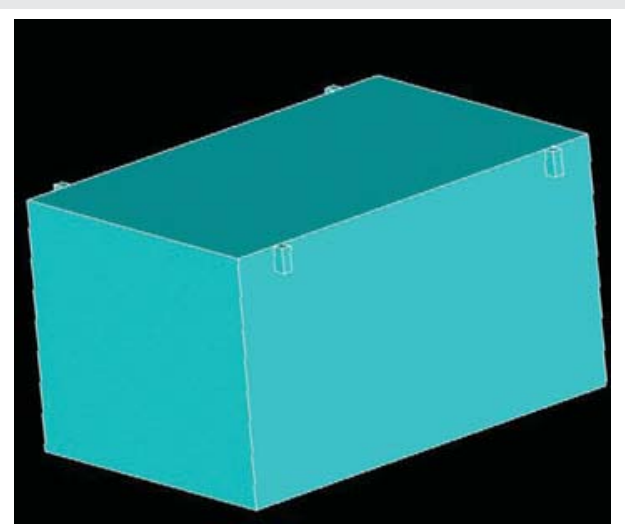

Figure 2: Four hinges in the numerical model to represent the real hinges.

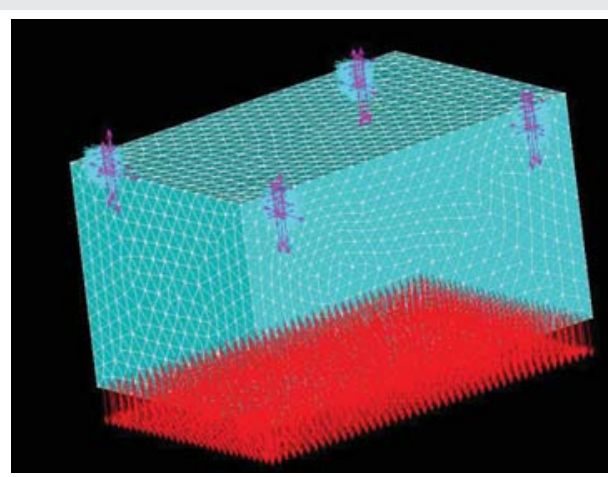

Figure 3: Finite element model of the classical container with applied displacement boundary conditions and loading. 
deflections on the base includes an effort to create distribution of forces on the certain site. This can be accomplished by a division of the force vector into two different directions, ideally in two equal different vectors with an angle of 45 degrees. The new base maintains the same thickness of the original model of a container which is $1 \mathrm{~cm}$ of thickness. As demonstrated in Figure 6 , the base of the container is replaced with a surface that permits this force distribution. The angle of the folds used is 45 degrees and the structure provides that the edges are clamped so that the optimal result can be achieved.

The new design is analyzed by FEM with the loads evenly distributed instead of the uniform distribution in the conventional container design analysis as shown in Figure 7. Although the volume increase in the base is $8 \%$ for the origami design, this new design concept is highly encouraging as the stresses decrease dramatically as demonstrated in Figure 8.

\section{Updated design based on origami concept without vo- lume restriction}

As the main goal remains the distribution of the force vectors, the second attempt relies on the first design using the same logic regarding the base and extends the usage of origami concept for the rest of the structure. The design proposed is influenced by the hexagonal cone origami design as shown in Figure 9 and is an attempt of the distribution of stress on the sides of the container as well. This second attempt will serve as an indicator for an advanced design without considering the increase of volume as long as desirable results can be achieved.

The design of folds on the sides of the container creates mechanical hinges that further permit energy absorption. This is possible through layers of material of opposite direction that face in and out of the box accordingly every one sixth of the

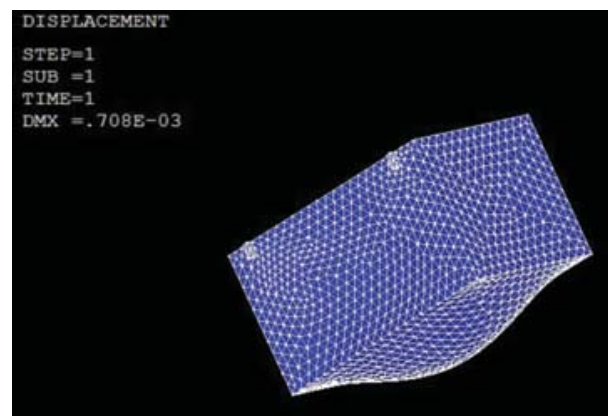

Figure 4: Deformed configuration of the classical container.
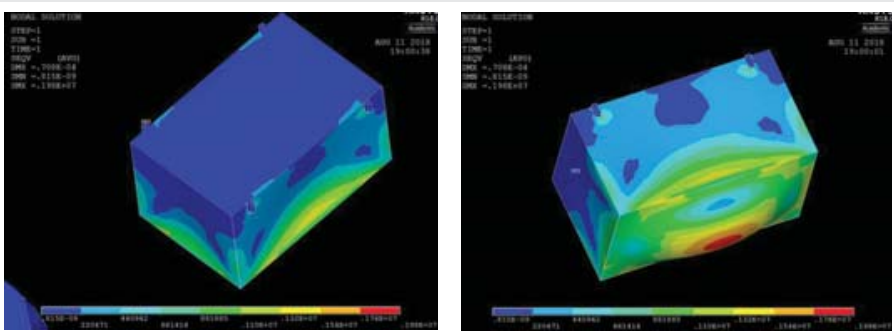

Figure 5: Von Mises Stress distribution inside the classical container.

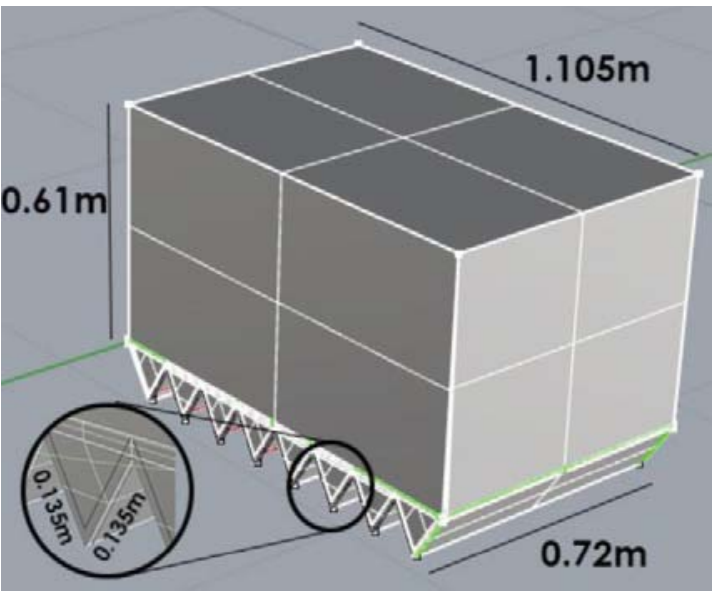

Figure 6: Conventional container with a folding base.

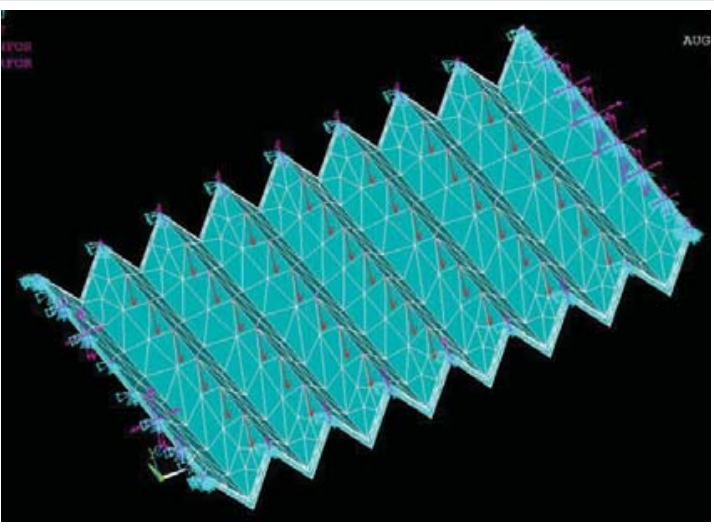

Figure 7: The folding base with the applied loads and constraints.

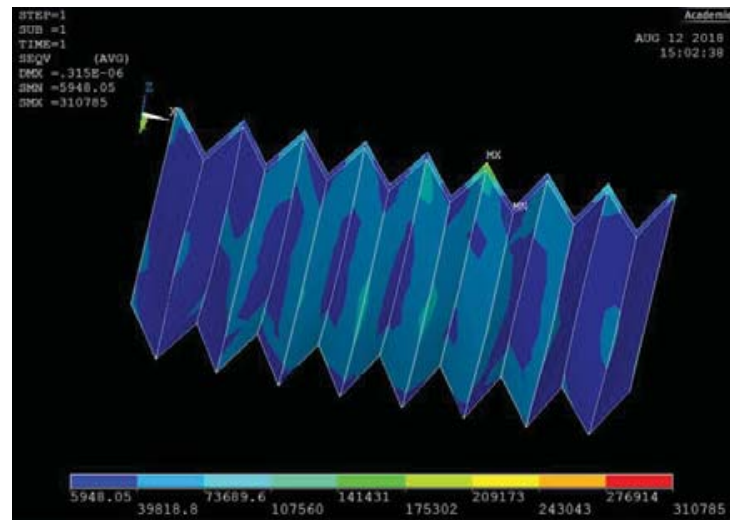

Figure 8: Von Mises Stress distribution at the folding base.

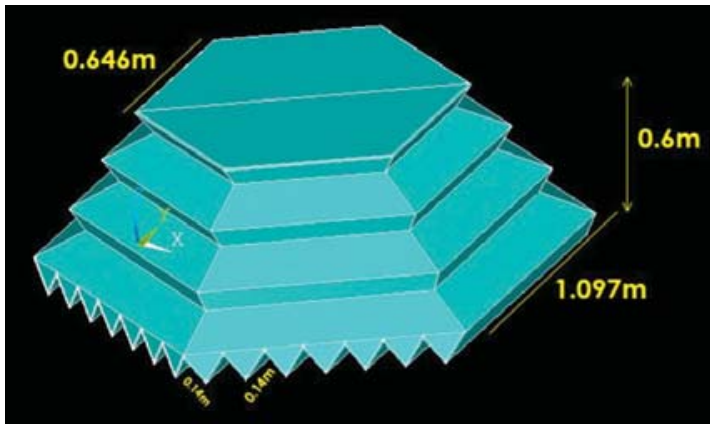

Figure 9: Geometrical properties of the hexagonal cone. 
height of the structure. This means that the mechanical hinges are created at $0.1 \mathrm{~m}, 0.2 \mathrm{~m}, 0.3 \mathrm{~m}, 0.4 \mathrm{~m}$, and $0.5 \mathrm{~m}$ on the vertical axis.

The same load as in the previous sections are applied and the von Mises stresses obtained from finite element analysis are presented in Figure 10. The results of the finite element analysis on the base and the upper part of the cone are satisfactory. However, there is an increase of volume, about $150 \%$, which is very costly. Another concerning issue is the concentration of stresses on the points of connection between the origami base and hexagon cone. Moreover, there is also high stress values on the hinges as well which requires further improvement on this design concept.

\section{Final design based on origami concept}

The final design concept is developed based on the three other concepts considered in this study. The concept of the origami folding base remains as used in previous concepts. Regarding the high stresses observed in the hexagonal cone, the levels of the container are now replaced with an oval shape instead of a polygon. As far as the folding along the sides of the container is concerned, the large folds of the previous concepts are substituted by one fold with the center hinge in the midheight of the container. The issue of the high stresses nearby the hinges is addressed with an extension of the origami influence to the surface of the container itself. This radically transforms the container surroundings by transforming it to a Miura-Ori veil that absorbs stresses all around as they are directed from the base where the load acts to the constrained hinges. In order to avoid large volume increase, the Miura-Ori fold was placed on a reduced thickness of $0.5 \mathrm{~cm}$ Figure 11.

A comparison of von Mises stress distribution obtained using the final Origami based design and conventional container design concepts is shown in Figure 12. The detailed comparison and discussion between different designs concepts considered in this student will be given in the following section.

\section{Conclusions}

Results obtained for all four different design concepts considered in this study can be summarized as:

- The biggest reduction in Von Mises stress can be detected in the case of the sole replacement of the base of the conventional container with an origami one and in the case of the hexagonal cone. However, in the case of the origami base there is no response to the high
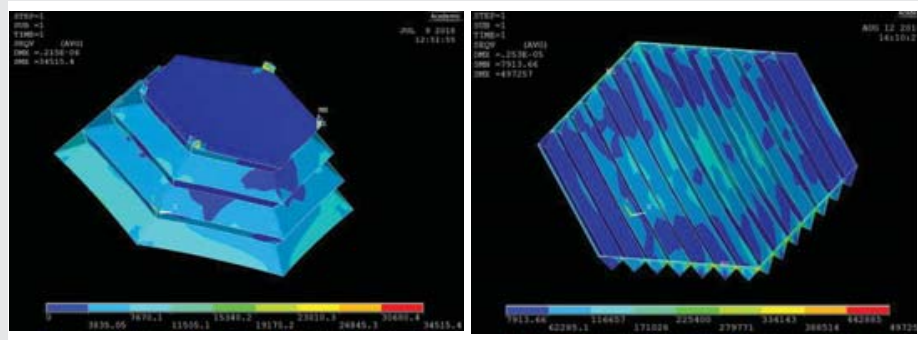

Figure 10: Von Mises Stress distribution in the hexagonal cone.

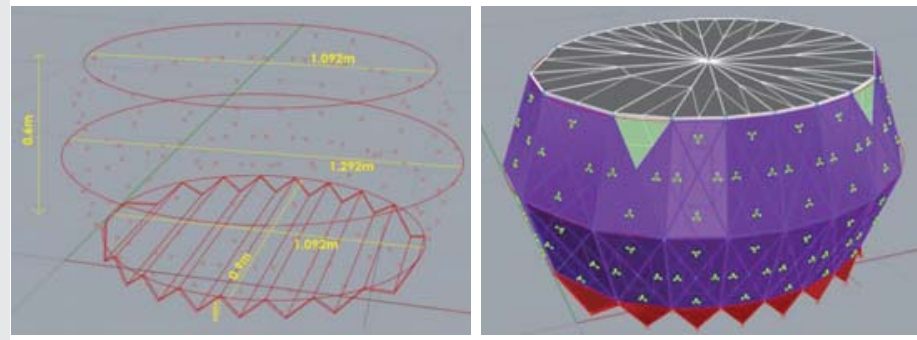

Figure 11: Final design based on Origami concept.

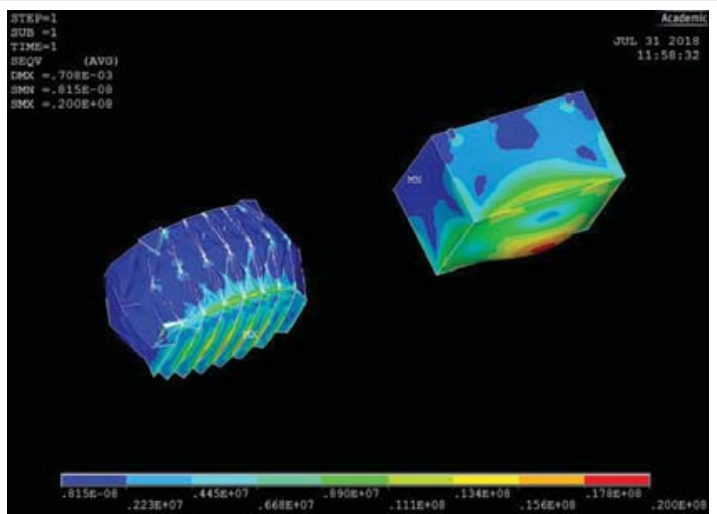

Figure 12: Comparison of Von Mises stress distribution in the final Origami based design (left) and conventional container design.

volumes of stress in the perimeter of the base and below the hinges whereas in the case of the hexagonal cone, even if the values overall are very promising, there is a significant increase in volume with respect to the conventional container design.

- In the case of the final design concept, the value of Von Misses is not reduced although it is heavily localized. Specifically, in the perimeter of the base in the conventional concept, the highest value is $1.54 \mathrm{MPa}$ whereas in the origami one the highest value is 1.1MPa. Below the hinges in the conventional container the highest value is 1.1MPa whereas in the origami design the highest value is $66414 \mathrm{~Pa}$ with a volume increase of $49 \%$.

Based on all four different design concepts considered in this study, it can be concluded that origami concept can provide certain advantages in terms of stress reduction with a price of volume increase in origami design concepts.

\section{References}

1. Ishida S, Nojima T, Hagiwara I (2014) Mathematical Approach to Model Foldable Conical Structures Using Conformal Mapping. J Mech Des 136: 091007. Link: http://bit.ly/2Gv07il

2. Norman M, Arjomandi K (2017) Origami Applications in Structural Engineering: A Look at Temporary Shelters. Proceedings of the $2^{\text {nd }}$ World Congress on Civil, Structural, and Environmental Engineering (CSEE'17). Link: http://bit.ly/2RWWQxY

3. Sugiura N, Nakamura Y, Tagawa H, Uno T, Okazaki S (2016) Design and fabrication of origami dome. Archicultural Interactions through the Silk Road $4^{\text {th }}$ International Conference, Mukogawa Women's Univ, Nishinomiya. 
4. Tseng $\mathrm{H}$ (2017) Analysis of design application on structural model of origami International Conference on Applied System Innovation (ICASI) 1857-1860. Link: http://bit.ly/204jaEO

5. Peraza-Hernandez AE, Hartl JD, Malak RJ Lagoudas DC (2014) Origamiinspired active structures: a synthesis and review. Smart Mater Struct 23 094001. Link: http://bit.ly/2uzk5Gp
6. Tolman SS, Delimont IL, Howell LL, Fullwood DT (2014) Material selection for elastic energy absorption in origami-inspired compliant corrugations. Smart Mater Struct 23: 094010. Link: http://bit.ly/2tVBcSQ

7. Schenk M, Guest SD (2010) Origami Folding: A Structural Engineering Approach. Link: http://bit.ly/2uAJVtE

\section{Discover a bigger Impact and Visibility of your article publication with}

\section{Peertechz Publications}

\section{Highlights}

* Signatory publisher of ORCID

* Signatory Publisher of DORA (San Francisco Declaration on Research Assessment)

* Articles archived in worlds' renowned service providers such as Portico, CNKI, AGRIS, TDNet, Base (Bielefeld University Library), CrossRef, Scilit, J-Gate etc.

* Journals indexed in ICMJE, SHERPA/ROMEO, Google Scholar etc.

* OAI-PMH (Open Archives Initiative Protocol for Metadata Harvesting)

* Dedicated Editorial Board for every journal

* Accurate and rapid peer-review process

* Increased citations of published articles through promotions

* Reduced timeline for article publication

Submit your articles and experience a new surge in publication services (https://www.peertechz.com/submission).

Peertechz journals wishes everlasting success in your every endeavours.

CopYRIGHT: (c) 2019 Antoniou K, et al. This is an open-access article distributed under the terms of the Creative Commons Attribution License, which permits unrestricted use, distribution, and $r$ eproduction in any medium, provided the original author and source are credited. 